\title{
Notifying a death in medicine
}

\section{Abstract}

The notification of death is one of the most difficult tasks for doctors, getting family members to understand the situation and being able to contain their emotions is a skill that is little developed by doctors. In view of this, we propose a communication model of the death of the patient in four steps described by the PHD MD José Félix Saavedra Ramírez, Specialist in Integrated Medicine. Assigned to the Internal Medicine service in a Public Hospital in Mexico City. ${ }^{1-3}$

Which are described as: 1) Preparation of the interview, 2) Find out how much you know about the condition, 3) Report the event in detail, 4) Freeing the family of emotional charge.

Keywords: death, emotions
Volume 5 Issue 5 - 2018

\author{
Jose Felix Saavedra Ramirez \\ Integrated Care Medicine Specialist, Santa Cruz Xochitepec, \\ Mexico
}

Correspondence: Jose Felix Saavedra Ramirez, Integrated Care Medicine Specialist, Santa Cruz Xochitepec, Mexico, Email dr-saavedra@hotmail.com

Received: August II, 2018 | Published:September II, 2018

\section{Introduction}

The objective of the doctors is to maintain the state of health, with the purpose of prolonging the life and the quality of life of the individual, the family and the community. This objective is achieved by undertaking actions aimed at effectively contributing to the education of the patient and their physical, family and social environment. Developing measures focused on prevention, restitution of health and efficiency of health services, through the use of scientific advances However, a natural aspect in the cycle of life is the conclusion of this. Where there is the organic impossibility of maintaining the homeostatic process reaching the state defined as biological death. Such an entity is approached differently according to the cultural, ideological or religious context of the relatives. However for the doctor, this fact according to their degree of maturity, translates into a psychological and emotionally complex situation. Since it must communicate this event to people in charge of the already deceased and few are doctors, who are with the skills to communicate it properly. In order to facilitate this task, we describe a practical and dynamic fourstep protocol, described by Dr. José Félix Saavedra Ramírez, using the Baile and Buckman model as a reference to communicate bad news. ${ }^{4-8}$

\section{Because it is difficult to communicate about a death}

The protocol described below is a practical four-step procedure to communicate the death of a patient. The doctors Walter F. Baile and Robert Buckman, together with their Oncology team had the idea of applying a protocol to the communication of bad news in Medicine; however this model was modified by the PHD, MD Jose Felix Saavedra Ramirez in an Institution Public of Mexico, ${ }^{9}$ with the purpose of communicating the death of a patient. ${ }^{10}$

\section{How to communicate - 4-step model}

\section{Step 1: preparation of the interview}

It is important to know the clinical record, the progress notes and the tests performed, to confirm the diagnosis. Most patients want to have certain relatives nearby at that time. Ask the patient if he wants to be accompanied by a family member. Sit down and invite the group to sit down. Being seated provides an atmosphere of seriousness and allows hundred percent of attention care of the family member. Start the interview with a greeting introducing yourself. ${ }^{11-13}$

\section{Step 2: discover how much you know about the condition}

This step is aimed at finding out how much the patient's condition knows the severity and the possible prognosis.

Begin the interview with a question ¿Do you know what illness your patient has and how severe it is? Clarify doubts about the disease. ${ }^{14,15}$

\section{Step 3: report the event in detail}

Use a simple and appropriate language at the intellectual and cultural level of the patient. Before citing the final event, it is convenient to use an introductory phrase such as: "I am afraid that your evolution is not what we expected". What will help the family to prepare for the blow and alleviate the emotional impact of the bad news? Avoid using technical terminology, euphemisms or medical jargon, Supply the information in small portions to allow time for the recipient to assimilate them. Leave pauses between phrases to allow the emotions of the patient and family to flow. $<<$ Indicate that all possible efforts and maneuvers were carried out according to the existence or not of the order not to resuscitate, duly recorded in the clinical file $>>$

\section{Step 4: freeing the family of emotional charge}

$<<$ This step constitutes the core point in the communication with the family member since it will reduce their emotional load $>>$ The phrase for more efforts that were made the body did not resist, I want to thank you for all the efforts of you and the family, because by bringing him you fulfilled what belonged. We, for the medical part did everything that was within our reach according to the existing medical and technological knowledge.

Close with these words. For more efforts of yours and ours, your body no longer resisted.

\section{Conclusion}

Although every doctor in clinical practice at least a couple of times has had to tell a relative about the death of a patient, there are few medical currents that instruct the doctor to give this bad news. That is why with this series of four steps, described above. The doctor has a tool, human and simple to communicate about the death of a patient, achieving a fair means between simplicity and effectiveness. Without falling into paternalism or coldness in communication.

\section{Acknowledgements}

None. 


\section{Conflict of interest}

The author declares that there is no conflict of interest.

\section{References}

1. Baile WF, Buckman R, Lenzi R, et al. SPIKES-A six-step protocol for delivering bad news: Applications to the patients with cancer. Oncologist. 2000;5(4):302-11.

2. Buckman R, Baile WF, Korsch B. A practical guide to communications skills in clinical practice. The countining education in nursing. 1999.

3. Fallowfield L. Living sad and bad news. Lancet. 1993;341(8843):476478.

4. Garg A, Buckman R, Kason Y. Teaching medical students how to break bad news. Can Med Assoc J. 1997;156(8):1159-1164.

5. Alves de Lima A. Cómo comunicar malas noticias a nuestros pacientes y no morir en el intento? Rev Argent Cardiol. 2003;71:217-220.

6. Hawken SJ. Strategies for dealing with the challenging patient. NZ Fam Physician. 2005;32:266-269.

7. Fallowfield L, Jenkins V. Communicating sad, bad, and difficult news in medicine. Lancet. 2004;363(9405):312-319.
8. Azoulay E, Chevret S, Leleu G, et al. Half the families of intensive care unit patients experience inadequate communication with physicians. Crit Care Med. 2000;28(8):3044-3049.

9. Núñez Díaz S, Martín-Martín AF, Rodríguez Palmero I, et al. Identificación de problemas de calidad en la información clínica a usuarios de un servicio de urgencias hospitalario. Rev Clin Esp. 2002;202(12):629-634.

10. Ordóñez Gallego A, García Girón C. La información médica al familiar: un aprendizaje. Med Clin (Barc). 1987;88:719-720.

11. Buckman R. Communications and emotions. Skills and effort are key. BMJ. 2002;325:672.

12. Randall Curtis J. Communicating with patients and their families about advance care planning and End-of-Life Care. Respir Care. 2000;45(11):1385-1394.

13. Truog RD, Cist AFM, Brackett SE, et al. Recommendations for end-oflife care in intensive care unit: The Ethics Committee of the Society of Critical Care Medicine. Crit Care Med. 2001;29(12):2332-2348.

14. Baile WF, Aaron J. Patient-physician communication in oncology: past, present, and future. Curr Opin Oncol. 2005;17(4):331-335.

15. Fallowfield L, Jenkins V. Farawell V. Enduring impact of communication skills training: results of a 12-month follow-up. $\mathrm{Br} J$ Cancer. 2003;89(8):1445-1149. 